\title{
Ontogenetic shifts in microhabitat preference of the temperate reef fish Forsterygion lapillum: implications for population limitation
}

\author{
Christopher J. McDermott, Jeffrey S. Shima* \\ School of Biological Sciences, PO Box 600, Victoria University of Wellington, Wellington 6001, New Zealand
}

\begin{abstract}
Quantitative surveys of habitat associations of New Zealand's common triplefin fish Forsterygion lapillum suggest that young settlers disproportionately occur within the fronds of the large brown algae Cystophora retroflexa and C. torulosa (hereafter collectively referred to as Cystophora). This apparent preference is specific to Cystophora (i.e. fish do not appear to respond to structurally similar macroalgal species) and is not exhibited by older juveniles or adults of the species, which suggests that age-specific microhabitat requirements may act as a bottleneck to recruitment. To determine whether the overuse of Cystophora by newly settled F. lapillum could be attributed to a behavioural preference for this specific habitat, we conducted a lab-based choice experiment. Using a purpose-built 'choice chamber' that facilitated assessments of behavioural responses of focal individuals provided with a choice of 4 common habitat types, we determined that newly settled F. lapillum selected chambers containing Cystophora more frequently than predicted by random assortment. To test the ecological consequences of this behavioural preference, we conducted a field experiment (replicated at 2 sites) that manipulated Cystophora cover and examined subsequent patterns of recruitment by F. lapillum. Experimental additions of Cystophora cover enhanced local recruitment of F. lapillum, and the effects of Cystophora additions were most pronounced at the site where Cystophora was naturally rare. Overall, these results suggest that age-specific behavioural preferences may mediate ontogenetic shifts in microhabitat use and limit recruitment in local populations.
\end{abstract}

KEY WORDS: Ontogenetic shift · Habitat preference $\cdot$ Forsterygion lapillum $\cdot$ Population bottleneck Population limitation $\cdot$ Choice chamber

\section{INTRODUCTION}

Many marine organisms use different habitats as they progress through their ontogeny (Werner \& Gilliam 1984). Most benthic or demersal marine organisms undergo a series of prominent habitat shifts, first when propagules are ejected into a pelagic environment and again when fully developed pelagic larvae settle back to the juvenile/adult benthic habitat (Thorson 1950, Caley et al. 1996). These transitions in habitat use are often accompanied by a large spatial displacement, and may have short-term benefits for organisms, such as reduced mortality achieved by moving vulnerable larvae away from predator-rich inshore adult habitats (Bonhomme \& Planes 2000). Large scale spatial displacement of larvae (i.e. dispersal) may also have longer term benefits for a species by allowing it to persist through small scale extinction events (Bonhomme \& Planes 2000).

In tropical reef systems, many reef-dwelling species appear to disproportionately use non-reef inshore habitats such as mangroves and seagrass beds as juveniles, and subsequently shift to offshore coral reef habitat as adults (Cocheret de la Morinière et al. 2002, Gillanders et al. 2003, Halpern 2004). These ontogenetic habitat shifts occur across 'intermediate' spatial scales (e.g. 100 s of meters to kilometres), and such observations have facilitated development of the 'nursery' concept, 
i.e. that certain habitats enhance growth and survival of juveniles (Rooker et al. 2004), and thus contribute disproportionately to overall recruitment into adult populations (Beck et al. 2001). Despite the intuitive appeal of the nursery habitat concept, relatively few studies have demonstrated a strong link between nursery and adult habitats (but see Halpern 2004).

Even less well understood are the demographic consequences of ontogenetic shifts in habitat use that prevail at much finer spatial scales. Shifts in microhabitat use over spatial scales of meters to $10 \mathrm{~s}$ of meters appear relatively common across a wide range of taxa, and have been described for tropical reef fish (Lirman 1994, Light \& Jones 1997, Vagelli 2004, Lecchini \& Galzin 2005), temperate reef fish (Carr 1989, Anderson 1994), flatfishes (Ryer et al. 2004), and sea urchins (Williamson et al. 2004). The explanations often invoked for such shifts are similar to those proposed for the role of nursery habitats, and include avoidance of intra-specific competition (density dependence) through resource partitioning (Lirman 1994), reduced predation rates (Carr 1989, Ryer et al. 2004), increased feeding efficiency, or a combination of factors (Dahlgren \& Eggleston 2000). All of the above explanations imply potentially strong effects of microhabitats on demographic rates (e.g. growth and/or survival, which eventuate into recruitment). At its extreme, stage-specific use of habitats, which are limiting, could lead to a demographic bottleneck that limits recruitment to later stages.

Many studies of ontogenetic shifts in habitat use are motivated (at least in part) by a desire to identify conservation hotspots, i.e. target areas for spatial management programmes such as marine reserves (Beck et al. 2001). To apply knowledge of stage-specific habitat use in effective management and conservation programmes, we must first identify the specific processes that drive such shifts, and then quantify the demographic consequences of these shifts. A common (and usually untested) assumption of studies of habitat use is that 'habitat association' is a result of some preference for a particular habitat (Crowe \& Underwood 1998). If such conclusions of mechanisms underlying habitat associations are erroneous (i.e. observed patterns of habitat association result from another mechanism, such as predation or competitive displacement) then conservation efforts that employ spatial management approaches may produce unexpected and potentially undesirable outcomes (Underwood et al. 2004).

Here, we used a preference index to statistically evaluate habitat associations of a temperate reef fish Forsterygion lapillum at 3 stages through its ontogeny: (1) as new settlers ( $<\sim 2$ wk post-settlement age), (2) as recruited juveniles ( $2 \mathrm{wk}$ to 6 mo post-settlement) and
(3) as reproductive adults (age $>\sim 6$ mo). We used a laboratory experiment to test a potential mechanism (behavioural preference) that underlies habitat association of newly settled F. lapillum. Finally, we manipulated percent cover of the habitat preferred by settlers in a field experiment to estimate the effects of habitat availability on recruitment.

\section{MATERIALS AND METHODS}

Study area and species. We conducted surveys and field experiments at multiple rocky reef sites along the Miramar Peninsula, Wellington, New Zealand (Fig. 1). Rocky reef habitat in this area is spatially discrete and relatively shallow (generally offshore of coastal headlands, comprised of cobbles, boulders, and/or rock outcrops persisting to a depth of up to $\sim 12 \mathrm{~m}$ ): discrete reefs are often separated by sandy embayments (C. J. McDermott pers. obs.). Our study species Forsterygion lapillum (the common triplefin) is endemic to New Zealand and is one of the most abundant reef fishes in our study area (C. J. McDermott pers. obs.). Adults spawn benthic egg masses on smooth rock or cobbles

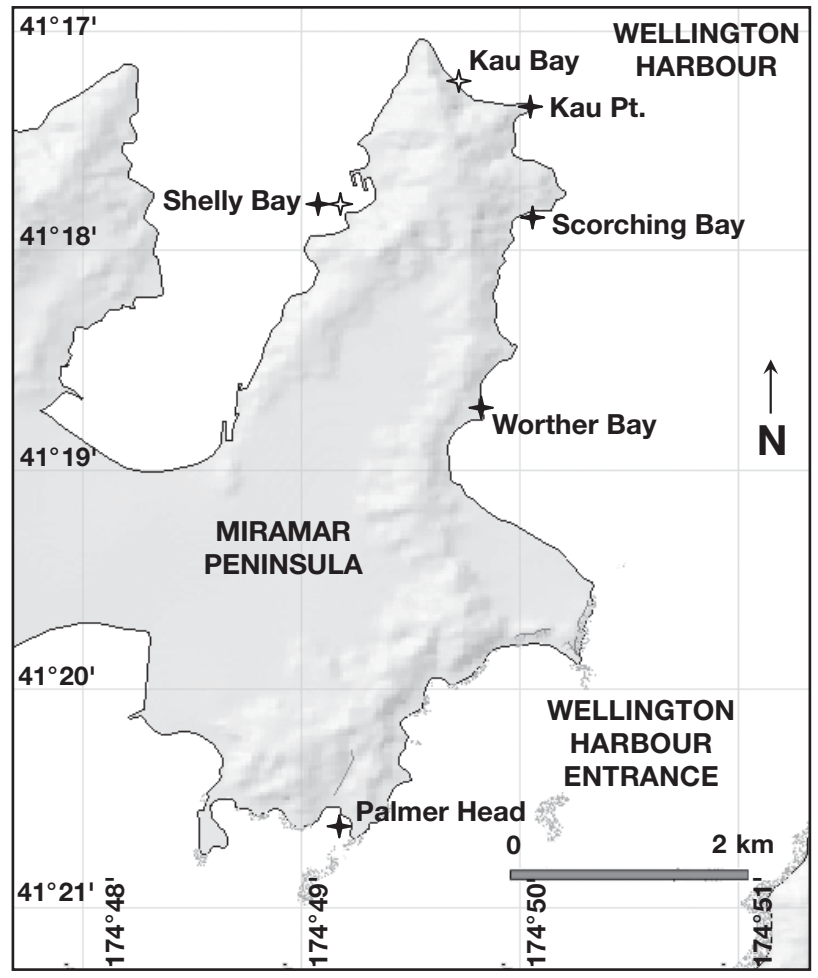

Fig. 1. Study sites. Black stars indicate locations of 5 sites surveyed for patterns of abundance and habitat use of Forsterygion lapillum. Open stars indicate 2 sites used in the experiment. Note: Kau Bay was not used in the original survey 
(often encrusted with coralline algae) between June and January (Francis 2001). New Zealand triplefins generally appear to be site-attached as adults, rarely ranging more widely than a few metres (Clements 2003). Pelagic larvae emerge from benthic eggs after 20 d (Francis 2001), and young F. lapillum generally settle back to rocky reef habitats in the Wellington region between November and March, after $~ 50$ days pelagic larval duration ( $\mathrm{PLD})(\mathrm{SD}=8.3$, J. S. Shima unpubl. data) and at an average size of $27.82 \mathrm{~mm} \mathrm{TL}$ ( $\mathrm{SD}=4.10 \mathrm{~mm}, \mathrm{~J}$. S. Shima unpubl. data).

We categorised 3 ontogenetic stages of Forsterygion lapillum based upon visually estimated size classes $(<30 \mathrm{~mm}, 30$ to $50 \mathrm{~mm}$, and $>50 \mathrm{~mm})$. These size classes were chosen to correspond roughly to age classes of 'new settlers' (average settlement size $27.82 \mathrm{~mm} \mathrm{TL}$ ), 'juveniles' (30 to $50 \mathrm{~mm}$ ) and 'adults' (>50 mm, approximate size that juveniles become sexually mature adults; Francis 2001). Forsterygion lapillum become sexually mature at $\sim 5 \mathrm{~cm}$ after $\sim 6$ mo (Francis 2001), and fish do not usually survive more than 2 breeding seasons (Doak 2003).

Patterns of habitat use. To quantify fish-habitat associations, we surveyed fish distributions relative to habitat composition at 5 sites around Miramar Peninsula (see Fig. 1). At each site we established 3 permanent $20 \mathrm{~m}$ transects parallel to shore. One transect was placed at a $3 \mathrm{~m}$ depth contour, and subsequent transects were placed parallel to this at a perpendicular distance of 10 and $20 \mathrm{~m}$ respectively. Average depth of all transects was $3.55 \mathrm{~m}(\mathrm{SD}=1.36)$, and transect depths did not vary significantly among sites $(p>0.05)$. Initial positions of transects were randomly determined. Along each transect we sampled $1 \mathrm{~m}^{2}$ quadrat at $5 \mathrm{~m}$ intervals $(\mathrm{n}=4$ quadrats per transect; 12 quadrats per site). All sites were sampled on 2 separate occasions 1 month apart in December 2003 and January 2004.

Within each quadrat we recorded visual counts of Forsterygion lapillum. We classified each fish into 1 of 3 size categories (see above) and recorded the microhabitat type (see list below) directly beneath each individual at the time of observation.

Following fish censuses, we visually estimated percent cover of the following 15 species/microhabitat categories: Cystophora, Carpophyllum maschalocarpum, Ecklonia radiata, Macrocystis pyrifera, Undaria pinnatifida, mid-water above bottom, geniculate coralline algae, encrusting coralline algae, bare rock and cobble, sand and broken shell, bare sand, small stones and pebbles $(<5 \mathrm{~cm}$ diameter), live mussels, dead mussel shells, and other encrusting invertebrates. Percent cover for the benthos and for the top of the overlying canopy (in an imaginary plane $\sim 30 \mathrm{~cm}$ above the bottom) was estimated separately within each quadrat. This gave a total estimated cover of $200 \%$ in each quadrat, which was subsequently additively standardised to a maximum value of $100 \%$.

We evaluated habitat use by new settlers, juveniles and adults separately using Manly's Alpha (Manly et al. 1972, Chesson 1978, Shima 2001). This measure is based on the proportion of fish within a given quadrat on a given habitat type, relative to the probability of the fish associating with that habitat type under conditions of random assortment, and is calculated as:

$$
\alpha_{i}=\frac{\frac{F_{i}}{H_{i}}}{\sum_{j=1}^{n} \frac{F_{j}}{H_{j}}} \quad i=1, \ldots, n
$$

where habitat use $(\alpha)$ is evaluated separately for each habitat type ( 1 through $n$ ) in each replicate sampling unit (quadrat), $H$ is the proportion of surveyed habitat of a given type, and $F$ is the proportion of censused fish on a given habitat type. We converted $\alpha_{i}$ values to electivities $\left(\varepsilon_{i}\right)$ to represent habitat use as an index ranging from -1 (never used) to +1 (exclusively used) with 0 representing neutral association, using the equation:

$$
\varepsilon_{i}=\frac{n \alpha_{i}-1}{(n-2) \alpha_{i}+1} \quad i=1, \ldots, n
$$

where $n$ is the number of habitat types (Chesson 1983). Manly's alpha and electivity values were calculated separately for each fish size class within each quadrat. Mean electivity values $( \pm 95 \%$ confidence intervals) were calculated for each microhabitat type, using quadrats as replicates.

Mechanism underlying habitat association: a behavioural preference? To test whether the observed pattern of overuse of Cystophora by newly settled Forsterygion lapillum (see 'Results') could be attributed to a behavioural preference for Cystophora, we constructed a 'choice-chamber' (modified from Lecchini et al. 2005; our Fig. 2).

A total of 102 newly settled Forsterygion lapillum (mean TL $=26.15 \mathrm{~mm}, \mathrm{SD}=2.17$ ) were collected from 3 sites around the Wellington south coast and harbour using clove-oil and hand nets. Subsequent analyses of otolith increments of another sample of F. lapillum suggested that individuals falling within this size distribution had a mean post-settlement age of $3.71 \mathrm{~d}$ ( $\pm 0.54,95 \%$ CI, J. S. Shima unpubl. data). Individuals were tested separately to evaluate their preference (inferred from movement patterns) for 1 of 4 microhabitats: Cystophora, Carpophyllum maschalocarpum, geniculate (erect) corallines on small rocks, and encrusting corallines on small rocks. Samples of microhabitat (sufficient to create $100 \%$ cover of a compartment) were distributed randomly among compart- 
ments 1 to 4 of the choice chamber. Carpophyllum maschalocarpum was chosen because it is a canopy forming macroalgae common to our study area, and is structurally similar to Cystophora. The 2 forms of coralline algae on rock were chosen as representative of much of the rocky reef substrate in our study area, and because these are known to provide settlement cues for some other species (e.g. abalone; Morse \& Morse 1984). The latter category was also the habitat that was disproportionately used by juvenile and adult F. lapillum.

Each individual was introduced to the central compartment of the choice chamber by means of a clear plastic release compartment (Fig. 2, compartment A). Following introduction to the release compartment, the focal fish was allowed to acclimatise for $1 \mathrm{~min}$ before the release compartment was lifted by a remote-operated pulley system to minimise disruption to the fish. Following release into the choice chamber, the movements of the focal fish were observed for 2 min (preliminary data suggested this duration was sufficient for a fish to make a 'choice'; see 'Results'). The first movement into 1 of the 4 adjoining compartments (Fig. 2, compartments 1 to 4) was scored as the choice for the focal fish.

At the end of each 2 min run, the fish was removed, fresh seawater was allowed to flow into the tank for $20 \mathrm{~s}$, and the water in the tank was briskly stirred with a plastic spatula. After a batch of 7 fish had been tested in this manner, microhabitat units were repositioned randomly among the 4 compartments. Following testing of 15 fish, the tank was drained so that seawater and microhabitat units could be completely replaced. These measures were taken to control for potential non-independence in the responses of individuals tested sequentially (e.g. arising from scent trails that might influence subsequent choices).

A chi-square analysis was used to test the $H_{0}$ that the 4 microhabitats were chosen in an equal frequency and, more specifically, to determine whether newly settled Forsterygion lapillum exhibit a behavioural preference for Cystophora.

Field manipulations of preferred habitat: consequences for recruitment? We manipulated Cystophora abundance (the microhabitat preferred by newly settled Forsterygion lapillum; see 'Results') to evaluate the effect of this behavioural preference on local recruitment. Using $2.25 \mathrm{~m}^{2}$ quadrats as our unit of replication, we established the following 4 treatments (n = 4 quadrats per treatment): 100\% Cystophora canopy cover, 25\% Cystophora canopy cover, 0\% Cystophora, and a disturbed control (with ambient Cystophora density). We duplicated this design at 2 sites (Shelly Bay and Kau Bay; see Fig. 1). At Shelly Bay, Cystophora was naturally abundant, while at Kau
Bay (approximately $1.5 \mathrm{~km}$ north-east) Cystophora was naturally rare. Consequently, construction of our experimental treatments involved removals and/or additions of Cystophora (using collected 'plants' with holdfast naturally attached to small cobbles) at Shelly Bay, and mainly additions of Cystophora at Kau Bay (using 'plants' collected from Shelly Bay). At each site, quadrats were arranged along a $3 \mathrm{~m}$ depth contour (parallel to shore), spaced $5 \mathrm{~m}$ apart, with treatments randomly assigned to quadrats. Cystophora density treatments were maintained by divers over the course of the experiment. Percent cover of Cystophora in control plots varied between sites: Shelly Bay plots had mean of $33.3 \%$ (SD = 45.4); Kau Bay plots had no ambient Cystophora. Recently settled F. lapillum were cleared from all quadrats prior to initiation of sampling.

Newly settled Forsterygion lapillum were censused visually within all quadrats, at 1 and 2 mo after establishment of treatments. Due to marking failures and/ or disturbance, several replicate quadrats were unable to be accurately identified for sampling. Consequently, statistical analyses were based upon an unbalanced design; however, all treatment $\times$ sample date combinations had sample sizes $\geq 2$. We tested the effect of Cystophora cover on recruitment of F. lapillum

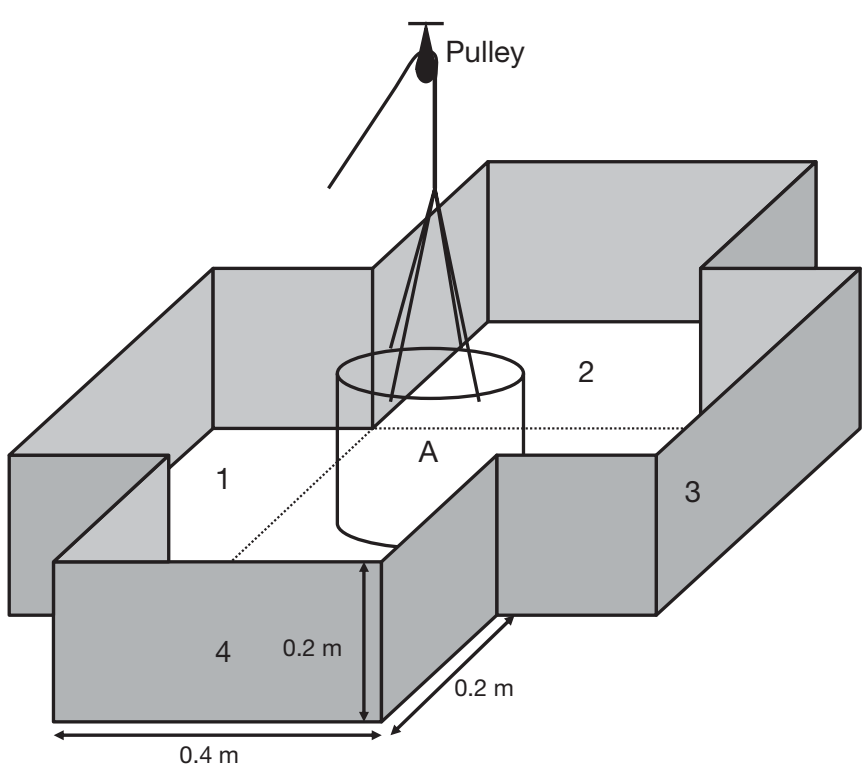

Fig. 2. Choice chamber design. Construction was of $3 \mathrm{~mm}$ clear plexiglass with all external walls masked with white waterproof paper. Four 'choices' presented to a focal individual were located in chambers 1 to 4 . Chamber A was a moveable clear plastic ring with holes around the bottom edge. This was used to acclimatise the focal individual to the chamber and allow it to sense a priori (through vision and olfaction) its 4 choices. Chamber A was lifted via remote pulley system, introducing the fish to the central arena where it was free to make its choice (ascertained as the first movement into any of the 4 chambers) 
using ANOVA with repeated measures (RM-ANOVA). Analyses were conducted using the generalised linear model (GLM) procedure of SPSS (version 11.5 for Windows), and all analyses met ANOVA assumptions.

\section{RESULTS}

\section{Patterns of habitat use}

Patterns of habitat use by newly settled Forsterygion lapillum (Fig. 3A) differed greatly from those of older juveniles (Fig. 3B) and adults (Fig. 3C), and suggested a possible ontogenetic shift in habitat use sometime after settlement. Settler electivities for Cystophora were strong, and although variable (likely a function of among-site variation in fish abundance relative to habitat percent cover), $95 \%$ CI did not overlap 0 (indicating a significant 'overuse' of this microhabitat type). Settling F. lapillum did not use Cystophora exclusively; settlers were also observed on Carpophyllum maschalocarpum, Macrocystis pyrifera, encrusting coralline algae, bare sand, and mid-water above bottom. Of these, only Carpophyllum and Macrocystis were used in proportion to their relative abundance; all other habitats were used far less often than expected by random chance. Juvenile and adult electivities for encrusting corallines (Fig. 3B,C) were both positive, with $95 \%$ CIs not overlapping 0 , which suggested a statistically significant overuse of this microhabitat type.

\section{Mechanism underlying habitat association}

The habitat preferences of 102 newly settled Forsterygion lapillum were evaluated in our choice chamber. The average time taken to make a 'choice' was $26.56 \mathrm{~s} \pm 3.46$ (mean $\pm \mathrm{SE}$ ) and only 8 fish failed to make a choice in less than $2 \mathrm{~min}$. Of the 94 fish that made a choice within 2 min: 36 chose Cystophora first, 27 chose Carpophyllum maschalocarpum first, 16 chose geniculate corallines first, and 15 chose encrusting corallines first. This distribution was significantly different from the $H_{0}$ distribution of $25 \%$ per habitat unit (i.e. with 94 fish, the $H_{0}$ distribution was 23.5: 23.5: 23.5: 23.5) $\left(\chi^{2}=12.64, \mathrm{df}=3, \mathrm{p}<0.01\right)$. Fig. 4 illustrates the distribution of behavioural choices exhibited by newly settled F. lapillum as the deviation from the expected distribution for each habitat type; Cystophora was chosen substantially more than the expected frequency, C. maschalocarpum was chosen slightly more than the expected frequency, while geniculate and encrusting corallines were chosen far less than expected. A second chi-square analysis was conducted to test whether Cystophora was chosen significantly more
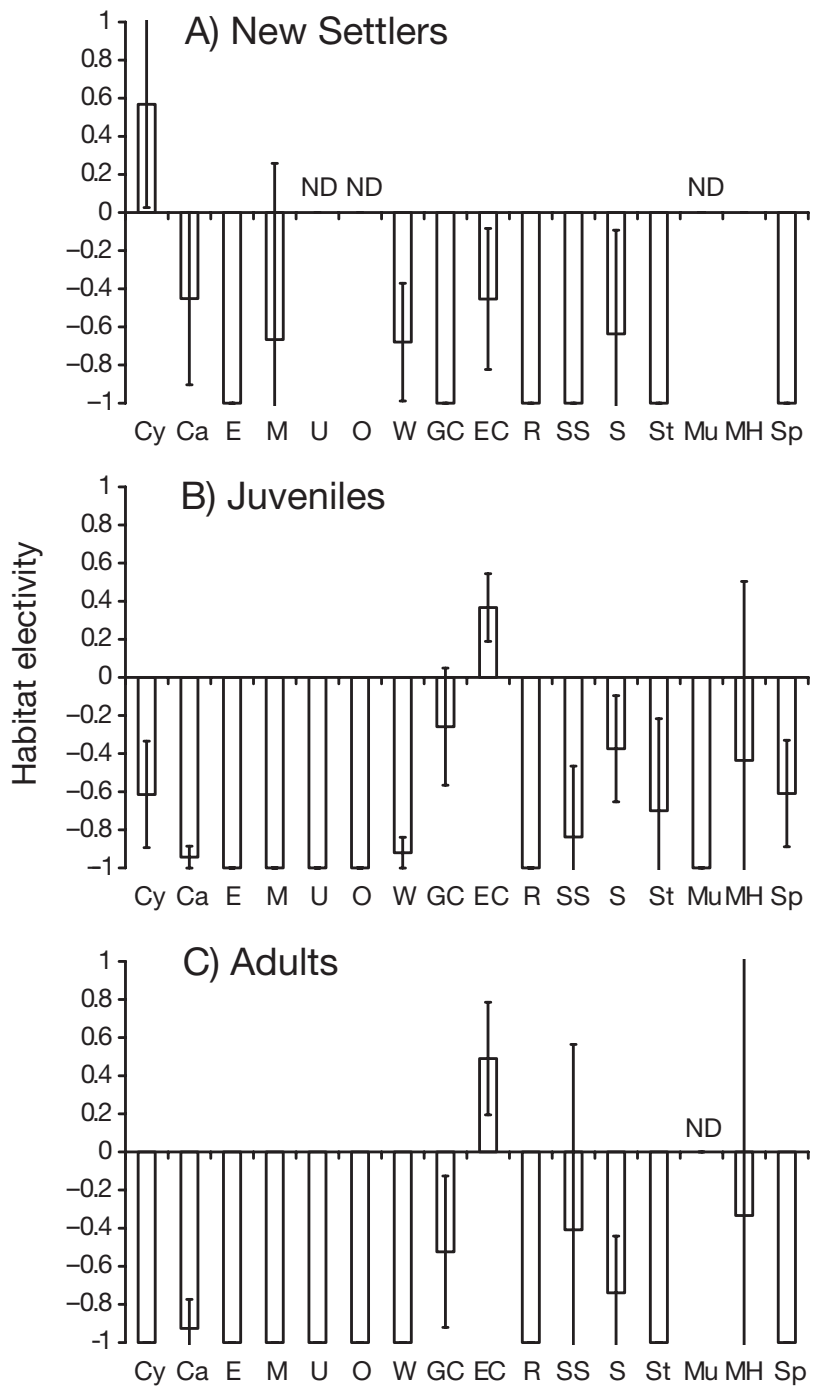

Fig. 3. Forsterygion lapillum. Patterns of habitat use by (A) recently settled individuals, (B) juveniles, and (C) adults. Data are electivity values calculated for each microhabitat category (mean $\pm 95 \% \mathrm{CI}$ ). Cy: Cystophora, Ca: Carpophyllum maschalocarpum, E: Ecklonia radiata, M: Macrocystis pyrifera, U: Undaria pinnatifida, O: other foliose macroalgae, W: mid-water above bottom, GC: geniculate coralline algae, EC: encrusting coralline algae, R: bare rock and cobbles, SS: sand and broken shell, S: bare sand, St: small stones and pebbles, Mu: live mussels, MH: mussel half shells (dead), Sp: other encrusting invertebrates (e.g. sponges and bryozoans), ND: habitat categories that never co-occurred with that age class of $F$. lapillum in sample quadrats

often than the other 3 habitat types (i.e. $H_{0}: P_{\mathrm{Cy}}=\left(P_{\mathrm{Ca}}+\right.$ $\left.P_{\mathrm{GC}}+P_{\mathrm{EC}}\right) / 3$, where Cy is Cystophora, Ca is Carpophyllum maschalocarpum, GC is geniculate coralline algae and $\mathrm{EC}$ is encrusting coralline algae). This test (a functional equivalent of a post hoc test) suggested that Cystophora was chosen significantly more often than would be expected under conditions of random assortment $\left(\chi^{2}=8.87, \mathrm{df}=1, \mathrm{p}<0.005\right)$. 


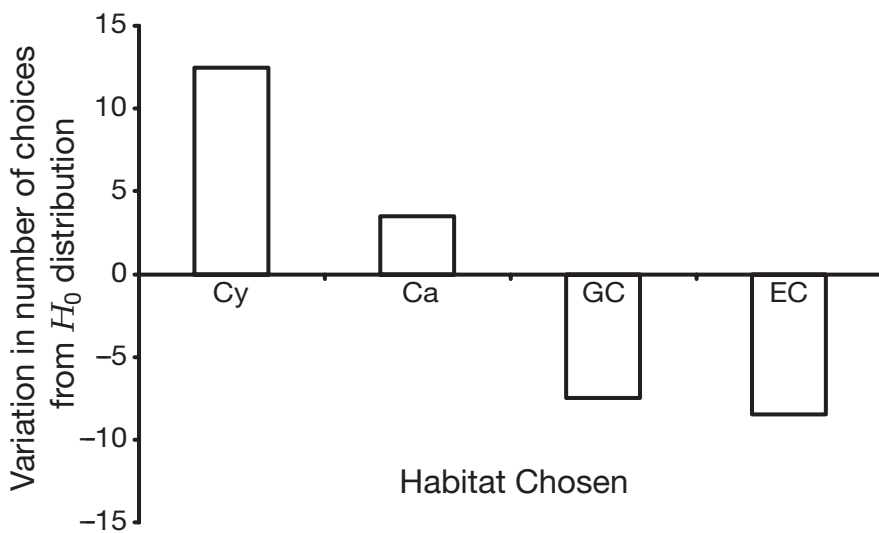

Fig. 4. Forsterygion lapillum. Behavioural preference for microhabitats, illustrated as deviation of habitat selection frequency from the expected $H_{0}$ distribution of 23.5:23.5:23.5: 23.5. Cy: Cystophora, Ca: Carpophyllum maschalocarpum, GC: geniculate coralline algae on cobbles, EC: encrusting coralline algae on cobbles

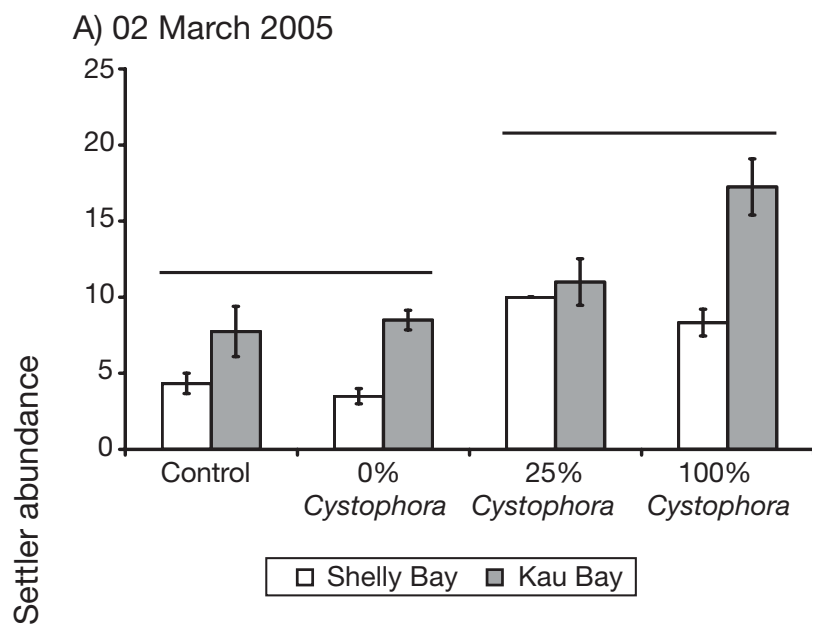

B) 12 April 2005

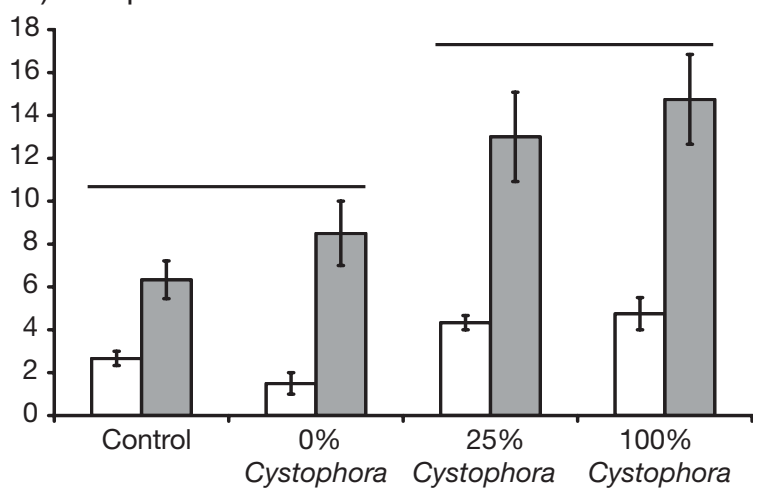

Fig. 5. Forsterygion lapillum. Average settler abundance as a function of experimentally manipulated Cystophora cover at Shelly Bay (unshaded) and Kau Bay (shaded) for (A) the March survey and (B) April survey (mean \pm 1 SE). Horizontal lines above graphs represent homogeneous subsets from post hoc Tukey test
Table 1. Forsterygion lapillum. Spatial variation in densities of settlers within experimental plots. Statistics from RMANOVA; data are from 2 repeat survey dates (02 March 2005 and 12 April 2005), 2 sites and 4 treatments

\begin{tabular}{|lccccc|}
\hline \multicolumn{7}{|l}{$\begin{array}{l}\text { I. Multivariate test (Wilk's } \lambda \text { ) } \\
\text { Effect }\end{array}$} & SS & df & MS & $F$ & p \\
\hline Date (D) & 28.529 & 1 & 28.529 & 3.916 & 0.067 \\
D $\times$ Site & 15.844 & 1 & 15.844 & 2.175 & 0.161 \\
D $\times$ Treatment & 1.659 & 3 & 0.553 & 0.076 & 0.972 \\
Error & 109.292 & 15 & 7.286 & & \\
& & & & & \\
II. Between subjects & & & & \\
Source & SS & df & MS & $F$ & P \\
\hline Site (S) & 393.390 & 1 & 393.390 & 393.390 & $<0.001$ \\
Treatment (T) & 293.229 & 3 & 97.743 & 97.743 & $<0.001$ \\
S $\times$ T & 101.238 & 3 & 33.746 & 33.746 & 0.023 \\
Error & 119.458 & 15 & 7.946 & & \\
\hline
\end{tabular}

\section{Manipulations of preferred habitat: consequences for recruitment}

Repeated surveys of Forsterygion lapillum recruits within experimental plots indicated significant amongsite variation and an effect of experimentally imposed Cystophora cover (Fig. 5A,B, Table 1). Overall recruitment to experimental plots was greater at Kau Bay (where Cystophora was relatively rare). Within each site, recruitment was enhanced by increasing densities of Cystophora; a post hoc Tukey test grouped control plots (with ambient densities of Cystophora) and $0 \%$ Cystophora as receiving similarly low levels of recruitment; 25\% Cystophora and 100\% Cystophora treatments had similarly high levels of recruitment. Analyses suggested a significant interaction between site and treatment effects: increasing Cystophora cover generally had a greater effect on settlement at Kau Bay.

\section{DISCUSSION}

Quantitative evaluations of habitat associations exhibited by newly settled, juvenile and adult Forsterygion lapillum suggest this species undergoes an ontogenetic shift in habitat use sometime after settlement. Newly settled F. lapillum overused Cystophora, whereas later age classes overused encrusting coralline algae. While such shifts in habitat use appear relatively common across a wide range of taxa in marine systems, the demographic consequences of these shifts are not well understood. Workers are generally quick to invoke adaptive explanations (e.g. resource partitioning, predator avoidance) to account for these patterns (Lirman 1994, Ryer et al. 2004); underlying mechanisms are rarely tested. 
Studies describing non-random habitat associations often leap to the conclusion that these are the result of a behavioural preference. As reviewed by Underwood et al. (2004), applying such interpretations to conservation and management strategies (if they are erroneous) may prove detrimental. While non-random patterns of association between an organism and a habitat may be a result of a behavioural preference for that habitat, apparent associations may also be driven through negative interactions between species. Inter- or intraspecific competition may extirpate a species (or a specific age-class) from preferred habitats into sites of poorer quality (with deleterious consequence for fitness). Predation may similarly remove species from habitats that would otherwise convey greater fitness. In such cases, leaping to the conclusion that an overused habitat is preferred by the focal species (or age-class) may lead to inefficient or ineffective management decisions - akin to treatment of symptoms rather than ailments. In this study, we determined that a non-random pattern of habitat use displayed by newly settled Forsterygion lapillum is at least partially the result of a behavioural preference for a specific habitat (Cystophora). Because we presumed this preference to be an evolutionary response to maximise fitness (e.g. optimal selection of sheltering and/or foraging habitats), we hypothesised that availability of this habitat might affect settlement of F. lapillum.

Our experimental manipulations of Cystophora density suggested that habitat availability facilitates recruitment of settler-sized Forsterygion lapillum. We replicated our experimental design at 2 sites. In doing this, we found that overall settlement to experimental plots was greater at Kau Bay: this may reflect spatial variation in larval supply (Kau Bay is closer to the mouth of Wellington harbour) and/or a dilution effect mediated by ambient (background) Cystophora densities (greater at Shelly Bay). The presence of a site $\mathrm{x}$ treatment interaction, coupled with observed patterns of settlement (Fig. 5) suggests that Cystophora additions produced a more 'graded' effect on settlement of F. lapillum at Kau Bay (where Cystophora was naturally rare), even though these graded trends were not statistically significant. Cystophora additions at Shelly Bay (where Cystophora was naturally common) appeared to have a 'saturating' effect on settlement when Cystophora additions exceeded $25 \%$ cover. Variation in ambient Cystophora cover between sites meant that our 'control' plots were not directly comparable, and this likely also contributed to the significance of the site $\times$ treatment interaction.

Taken separately, the 3 core components of this study-observed patterns of habitat use by newly settled Forsterygion lapillum, lab-based habitat choice experiments, and field manipulations of habitat avail- ability - provide circumstantial evidence for habitat limitation. Alone, statistical overuse of Cystophora from our survey data may indicate a 'preference' for this microhabitat (e.g. for foraging habitat and/or as a refuge from predators). Cystophora is a structurally complex seaweed and is known to support greater densities of epifauna (a potential food source for young F. lapillum) relative to other brown algae (Taylor \& Cole 1994, Taylor 1998). However, few inferences can be drawn from the survey data about the mechanisms (e.g. larval attraction, differential post-settlement migration or mortality) driving such patterns of association without additional data.

Similarly, taken alone, results from the lab-based choice experiment likely indicate a 'preference' for Cystophora over 3 other common microhabitats, but the empirical implications and mechanisms underlying these results remain elusive. While the individuals used in laboratory trials were presumed to be recently settled based upon their size (otolith analyses of similarly sized fish suggest that $95 \%$ of the individuals trialled were less than $4.25 \mathrm{~d}$ post-settlement age), they were not 'naïve' in a strict sense, and a disproportionate number of these fish were likely collected from Cystophora habitat. Consequently, laboratory choice experiments alone did not enable us to differentiate between (1) larval preference for Cystophora as a 'settlement habitat' and (2) an affinity for Cystophora developed during post-settlement experience.

Lastly, while the field manipulations of Cystophora provide the strongest evidence for habitat limitation, results from this activity alone do not facilitate inferences of mechanisms underlying the positive effects of Cystophora on local recruitment (e.g. attributable to enhanced larval settlement versus post-settlement survival and/or migration). Existing evidence suggests that New Zealand triplefins are exceptionally siteattached after settlement (Clements 2003), so we expect that post-settlement migration is not a sole explanation for our results. Consequently, we infer from our experimental results that the local abundance of Cystophora has a strong effect on local recruitment of Forsterygion lapillum, possibly attributable to enhanced settlement and or post-settlement survival.

The strength of our study lies in the complementarity of our approach. Overall, our results from these 3 complementary research components suggest that patterns of non-random microhabitat use observed for Forsterygion lapillum are, in part, driven by the behavioural preferences of specific age-classes. Because these habitat preferences are likely to arise from fitness maximising strategies, we expected availability of preferred habitat to have strong effects on patterns of settlement. Our experimental manipulations of preferred habitat confirmed a strong habitat-mediated demographic re- 
sponse by F. lapillum. Taken together, our work suggests that behavioural preferences that vary through ontogeny can facilitate a 'recruitment bottleneck' and contribute to the limitation of local populations.

Acknowledgements. This research was funded by Victoria University of Wellington and by the Royal Society of New Zealand, in a Marsden grant to J.S.S. S. Pledger provided useful input to statistical analyses, and the manuscript further benefited from the comments of 3 anonymous reviewers.

\section{LITERATURE CITED}

Anderson TW (1994) Role of macroalgal structure in the distribution and abundance of a temperate reef fish. Mar Ecol Prog Ser 113:279-290

Beck MW, Heck KL Jr, Able KW, Childers DL and 9 others (2001) The identification, conservation, and management of estuarine and marine nurseries for fish and invertebrates. BioScience 51:633-641

Bonhomme F, Planes S (2000) Some evolutionary arguments about what maintains the pelagic interval in reef fishes. Environ Biol Fish 59:365-383

Caley MJ, Carr MH, Hixon MA, Hughes TP, Jones GP, Menge BA (1996) Recruitment and the local dynamics of open marine populations. Annu Rev Ecol Syst 27: $477-500$

Carr MH (1989) Effects of macroalgal assemblages on the recruitment of the temperate zone reef fishes. J Exp Mar Biol Ecol 126:59-76

Chesson J (1978) Measuring preference in selective predation. Ecology 59:211-215

Chesson J (1983) The estimation and analysis of preference and its relationship to foraging models. Ecology 64: $1297-1304$

Clements K (2003) Triplefins. In: Andrew N, Francis M (eds) The living reef: the ecology of New Zealand's rocky reefs. Craig Potton Publishing, Nelson, p 160-167

Cocheret de la Morinière E, Pollux BJA, Nagelkerken I, van der Velde G (2002) Post-settlement life cycle migration patterns and habitat preference of coral reef fish that use seagrass and mangrove habitats as nurseries. Estuar Coast Shelf Sci 55: 309-321

Crowe TP, Underwood AJ (1998) Testing behavioural 'preference' for suitable microhabitat. J Exp Mar Biol Ecol 225: $1-11$

Dahlgren CP, Eggleston DB (2000) Ecological processes underlying ontogenetic habitat shifts in a coral reef fish. Ecology 81:2227-2240

Doak W (2003) A photographic guide to sea fishes of New Zealand. New Holland Publishers, Auckland

Francis M (2001) Coastal fishes of New Zealand: an identifica-

Editorial responsibility: Steven G. Morgan (Contributing

Editor), Bodega Bay, California, USA tion guide, 3rd edn. Reed Books, Auckland

Gillanders BM, Able KW, Brown JA, Eggleston DB, Sheridan PF (2003) Evidence of connectivity between juvenile and adult habitats for mobile marine fauna: an important component of nurseries. Mar Ecol Prog Ser 247:281-295

Halpern B (2004) Are mangroves a limiting resource for two coral reef fishes? Mar Ecol Prog Ser 272:93-98

Lecchini D, Galzin R (2005) Spatial repartition and ontogenetic shifts in habitat use by coral reef fishes (Moorea, French Polynesia). Mar Biol 147:47-58

Lecchini D, Shima J, Banaigs B, Galzin R (2005) Larval sensory abilities and mechanisms of habitat selection of a coral reef fish during settlement. Oecologia 143:326-334

Light PR, Jones GP (1997) Habitat preference in newly settled coral trout (Plectropomus leopardus, Serranidae). Coral Reefs 16:117-126

Lirman D (1994) Stegastes planifrons (Cuvier) in Roatan Island, Honduras. J Exp Mar Biol Ecol 180:71-81

Manly BFJ, Miller P, Cook LM (1972) Analysis of a selective predation experiment. Am Nat 106:719-736

Morse ANC, Morse DE (1984) Haliotis larvae induced by molecules uniquely available at the surfaces of crustose red algae. J Exp Mar Biol Ecol 75:191-215

Rooker JR, Landry AM, Geary BW, Harper JA (2004) Assessment of a shell bank and associated substrates as nursery habitat of postsettlement red snapper. Estuar Coast Shelf Sci 59:653-661

Ryer CH, Stoner AW, Titgen RH (2004) Behavioral mechanisms underlying the refuge value of benthic habitat structure for two flatfishes with differing anti-predator strategies. Mar Ecol Prog Ser 268:231-243

Shima JS (2001) Recruitment of a coral reef fish: roles of settlement, habitat, and postsettlement losses. Ecology 82: $2190-2199$

Taylor RB (1998) Density, biomass and productivity of animals in four subtidal rocky reef habitats: the importance of small mobile invertebrates. Mar Ecol Prog Ser 172:37-51

Taylor RB, Cole RG (1994) Mobile epifauna on subtidal brown seaweeds in northeastern New Zealand. Mar Ecol Prog Ser 115:271-282.

Thorson G (1950) Reproductive and larval ecology of marine bottom invertebrates. Biol Rev 25:1-45

Underwood AJ, Chapman MG, Crowe TP (2004) Identifying and understanding ecological preferences for habitat or prey. J Exp Mar Biol Ecol 300:161-187

Vagelli AA (2004) Ontogenetic shift in habitat preference by Pterapogon kauderni, a shallow water coral reef apogonid, with direct development. Copeia 2004(2):364-369

Werner EE, Gilliam JF (1984) The ontogenetic niche and species interactions in size-structured populations. Annu Rev Ecol Syst 15:393-425

Williamson JE, Carson DG, De Nys R, Steinberg PD (2004) Demographic consequences of an ontogenetic shift by a sea urchin in response to host plant chemistry. Ecology 85:1355-1371

Submitted: October 7, 2005; Accepted: January 18, 2006

Proofs received from author(s): August 11, 2006 